\title{
Mapeamento e caracterização da densidade da vegetação Bacia Hidrográfica do Rio Paraíba do Meio.
}

\author{
Mapping and characterization of density Hydrographic Basin vegetation of the Rio Paraiba \\ do Meio.
}

\author{
RAMOS $^{1}$, R. P. S.; DEUS ${ }^{1}$, R. A. S. G; ALEXANDRE ${ }^{1}$, F. S.; GOMES ${ }^{2}$, D. D. M.; \\ GOLDFARB $^{3}$, M. C. \\ renilsonr5@hotmail.com
}

\begin{abstract}
Resumo
O presente trabalho teve como objetivo a análise da densidade da vegetação da bacia do rio Paraíba do Meio. No primeiro momento foi feito um levantamento bibliográfico sobre a área alvo deste estudo, com os dados de levantamento foi alcançado algum embasamento para fundamentar esse trabalho. Com esses dados foi possível fazer um banco de dados para melhor uso dos datas no processamento. Os dados foram processados no software ArcGIS 10.3.1, duas cenas foram utilizados para calcular o NDVI, SAVI e SR, índices de vegetação que é geralmente usado para estudos sobre a densidade da vegetação de forma eficaz. Os resultados do cálculo do NDVI, SAVI e SR foi usado em um processamento para fazer com que as duas cenas se tornassem apenas uma, um mosaico, as duas cenas utilizados são do satélite Landsat 8, que usa o sensor OLI. Para delimitar a bacia do rio Paraíba do Meio foi utilizado outro processamento no ArcGIS 10.3.1, utilizando também duas cenas, mas agora da outra missão, o Modelo Digital de Elevação da SRTM. Com a bacia delimitada foi possível extrair a bacia do mosaico das duas cenas do Landsat 8, para fazer as análises nos resultados do NDVI, SAVI e SR, em seguida, com as datas foi possível elaborar classes para classificar a densidade do vegetação.
\end{abstract}

Palavras-chave: Geoprocessamento, Bacia Hidrográfica, vegetação.

\begin{abstract}
This Paper had how goal the analyzes of the density of the vegetation of watershed of Paraíba do Meio river. In the first moment was made a bibliographic lifting about the area target of this study, with the lifting data were achieved some to be the fundament of this paper. With this data was possible to make a database to be better of use the data in the processing. The data were processed in software ArcGIS 10.3.1, two scenes were used to calculate the NDVI, SAVI and SR, vegetation indexs that is usually used to studies about the density of vegetation, for to be effective. The results of calculation of the NDVI, SAVI and SR was used in a processing to make with that the two scenes come to be just one, a mosaic, the two scenes used are of the satellite Landsat 8, that use the sensor OLI. To delimit the watershed of the Paraíba do Meio river was used other processing in ArcGIS 10.3.1, using also two scenes, but now of the another mission, the digital model elevation of the SRTM. With the basin delimited was possible extract the watershed of the mosaic of the two scenes of the Landsat 8, to make the analyzes in the results of the NDVI, SAVI and SR then with the data was possible to make class to rank the density of the vegetation.
\end{abstract}

Keywords: Geoporcessing, Watershed, Vegetation.

\section{INTRODUÇÃ̃O}

Devido a constante necessidade de monitoramento ambiental, para que tenha-se uma base de dados para que sirva de embasamento para a formulação de planos de gestão territorial, é preciso fazer análises acerca de determinadas áreas que podem se caracterizar como possuidoras de um potencial econômico.

'Renilson Pinto da Silva Ramos, Rodolfo Alexandre da Silva Gomes de Deus, Fernando da Silva Alexandre Geografia / Geoprocessamento e Modelagem Ambiental, Universidade de Pernambuco, Garanhuns-PE, Brasil.

${ }^{2}$ Daniel Datnas Moreira Gomes, Geografia / Geoprocessamento e Modelagem Ambiental, Universidade de Pernambuco, Garanhuns-PE, Brasil.

${ }^{3}$ Maurício Costa Goldfarb, Matemática / Geoprocessamento e Modelagem Ambiental, Universidade de Pernambuco, Garanhuns-PE, Brasil. 
Com essa crescente necessidade da gestão territorial, também crescem os meios para realizar-se esse monitoramento, em países com territórios de grande extensão, como o Brasil, é interessante e mais econômico para o estado o uso de geotecnologias. O Sensoriamento Remoto e o Geoprocessamento acabam por serem proeminentes no âmbito de monitoramento ambiental, fazendo com que consiga-se informações de determinada área sem ser necessário que se tenha contato com o mesmo meio, e quando esses dados são auferidos, então as técnicas computacionais de manejo e manipulação desses dados, somados com as técnicas de Cartografia.

Assim o Sensoriamento Remoto e o Geoprocessamento se tornam ferramentas de uso eficiente no monitoramento ambiental, e em gerar dados que serão base de futuros planejamentos para ordenamento territorial. As geotecnologias que são novas tecnologias com base das geociências, e podem ser usadas em pesquisas, planejamentos e em processos de gestão ambiental, sendo bastante eficientes quando os alvos dos estudos são locais que compreendem uma grande área (FITZ, 2008).

Há uma necessidade que o homem vem a ter acerca da gestão de seus recursos naturais, para então assim poder realizar planejamentos para sua gestão, para que se processe os interesses de um determinado órgão, governamental ou não, mas os governamentais com o conhecimento para realizar o necessário planejamento, deve visar suprir necessidades humanas que pode vir a surgir no futuro, mas não apenas aplicando esse conhecimento para o planejamento em apenas questões sociais, pois os humanos assim como um ser social, também deve entender que é um ser animal, parte do ambiente em que vive, mostrando que a questão ambiental, também é uma questão social, pois é nesse espaço ambiental que ocorrem as atividades sociais (ROSS, 1991.)

Uma Bacia hidrográfica é definida por uma área de terra que é possuidora de canais hidrográficos, e que reúnem-se, saindo de nascentes, que desembocam em uma rio principal através de um sistema hídrico, levando as águas através desse rio principal até sua foz, podendo ser outros rios maiores, grandes lagos, ou mais comumente, o mar. Leis no Brasil falam acerca da necessidade do conhecimento da área que compreende uma bacia hidrográfica, Lei ${ }^{\circ}$ 9. 433/97, por reconhecerem o potencial econômico que possui uma área como essa, e também como tal área acaba por influenciar em toda dinâmica social das área inseridas dentro do perímetro que compreende a bacia hidrográfica, muitas vezes tendo ligação direta com os habitantes da região, sendo provedora de abastecimento líquido local, ou de fornecimento de algum tipo de atividade econômica para a área, como a pesca, tendo em vista assim que o conhecimento das características que compõe uma bacia hidrográfica é de suma importância para o planejamento da gestão dos recurso hídricos, que é uma necessidade reconhecida por lei.

Tem-se ideia de que a vegetação e de sua importância acerca de que ela acaba por prover uma certa defesa do solo diante da erosão das erosões ocasionadas pelos efeito splash, da pluviometria causando erosão pela pluviosidade de uma determinada área, sem essa defesa que a vegetação ocasiona, um maior índice de erosão pode ser considerado na área a ser estudada, e consequentemente um menor índice de escoamento de subterrâneo, devido ao alto índice de escoamento superficial, devido ao fato do aparo de que a vegetação pode ocasionar (LIMA, 2015). 
Ter ideia da quantidade de vegetação que existe em um local é algo de extrema importância para qualquer tipo de planejamento que vise a gestão dos recurso de determinada localidade, pois intensidade dessa vegetação é o que vem a definir como os solos do local podem ser protegidos, ou não, do assoreamento causado por precipitações, as vegetações das mais variadas formas acabam por funcionar como maneira de interceptação das precipitações evitando que a energia contida na gota d'água atinja o solo e cause danos a ele (TRICART, 1977).

O uso de sensoriamento remoto para identificação da vegetação e de suas variações tende a ser bastante utilizados nos meios de estudo do Sensoriamento Remoto, pela forma que a vegetação interage com a radiação do espectro eletromagnético, que é um resultado complexo que tem um grande número de variações e questões ambientais, que ao estudo e realização de análises envolvendo Sensoriamento Remoto e vegetação deve-se levar em conta, como folhas, frutos, galhos e folhas, onde quando ocorre a interação com a energia eletromagnética, há processos de espalhamento e absorção, gerando fluxos que terão resultados dependendo das características físico-químicas dos elementos contido na vegetação considerada (PONZONI, 2002).

A bacia hidrográfica que foi escolhida objeto de análise, é a bacia hidrográfica do rio Paraíba do Meio, que fica localizada nos estados de Pernambuco e Alagoas, entre $8^{\circ} 45^{\prime \prime}$ e $9^{\circ} 30^{\prime \prime}$ de latitude sul, e $35^{\circ} 55^{\prime \prime}$ e $36^{\circ} 50^{\prime}$ de longitude oeste (Figura 1), ocupando uma área de $3136,8 \mathrm{Km}^{2}$ e abrangendo oito município Pernambucanos e oito alagoanos, tendo 192, $53 \mathrm{Km}$ de sua nascente até sua foz.

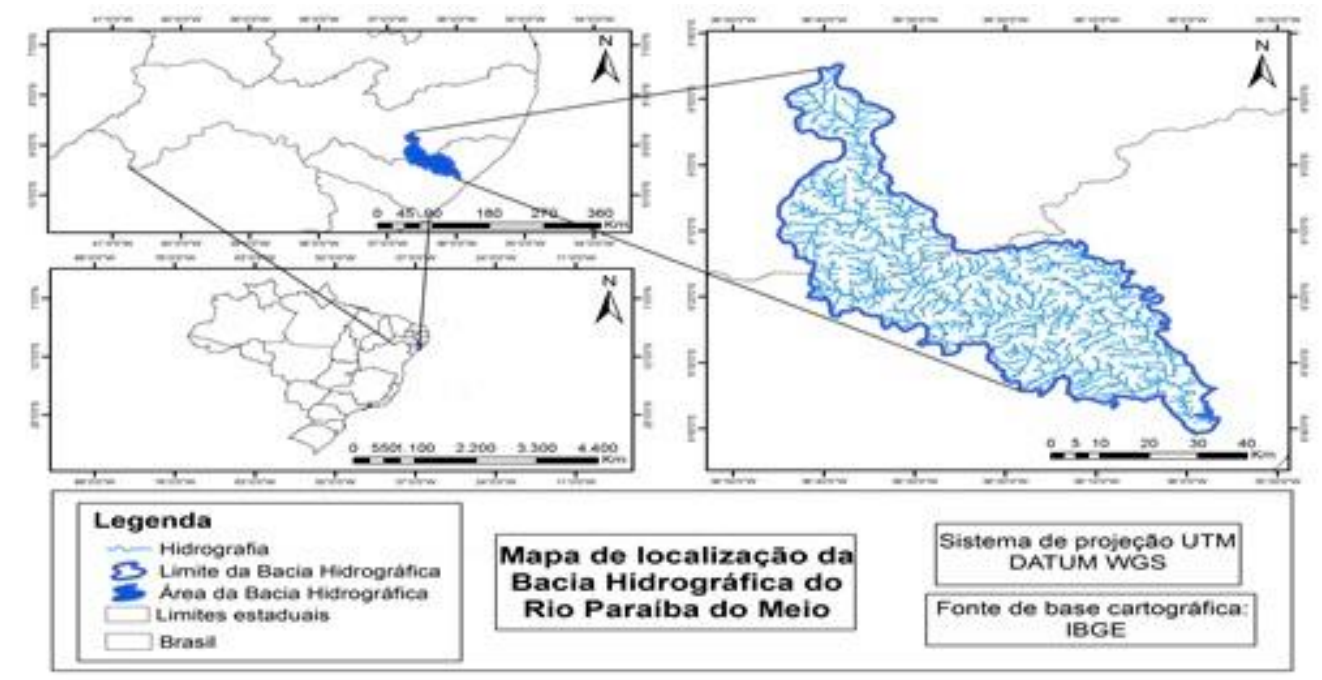

Figura 01: Mapa de localização da bacia hidrográfica do rio Paraíba do Meio. Fonte: Autor Renilson Pinto da Silva Ramos.

\section{METODOLOGIA}

No primeiro momento foi levantado todo um material bibliográfico, contendo artigos, livros, manuais técnicos, mapas e dados cartográficos acerca da bacia e vegetação da área estudada, e dos arredores, para que sirva de embasamento para sustentar as ideias propostas durante o trabalho.

Os dados altimétricos que foram utilizados, foram advindos da missão SRTM (Shuttle Radar Topographic Mission), de 30 metros, disponibilizadas pela USGS (United States Geological Survey) 
auferidas em http://earthexplorer.usgs.gov, enquanto as cenas utilizadas foram s09_w036_1arc_v3 e s10_w036_1arc_v3, para a delimitação da Bacia Hidrográfica, utilizada para definir os parâmetros para os limites da área.

Foram utilizadas para a delimitação da área ferramentas do software ArcGis 10.3.1, depois de ter utilizado métodos para gerar um mosaico, união das cenas do SRTM, onde a partir do MDE, modelo digital de elevação, foi possível definir os limites da bacia hidrográfica alvo do estudo.

As cenas utilizadas foram obtidas também através da disponibilização dos dados pela USGS, foram duas cenas, do satélite Landsat 8, que utiliza o sensor OLI (Operational Land Imager), uma do ponto 214, da rota 67 , e a outra do ponto 215 , da rota 67 , datadas de 11/02/2016 e 30/11/2015, respectivamente.

Com os dados auferidos através das duas cenas do Landsat 8, foi realizado o cálculo do NDVI, o índice de vegetação por diferença normalizada, que é realizado dentro das ferramentas disponíveis pelo software da empresa ESRI, ArcGis 10.3.1, subtraindo o infravermelho próximo da banda do vermelho, e com o resultado, dividindo com o resultado da soma do infravermelho próximo com o vermelho, que corresponde a banda $4(0,630$ - 0,680 micrômetros) e a banda $5(0,845-0,885)$ do sensor OLI respectivamente. O Cálculo é realizado na calculadora Raster que está inserida dentro do software, o resultado do NDVI, tem uma escala de cinza que varia de +1 até -1 , utilizando a equação:

\section{NDVI = IVP-V/IVP+V}

A partir dos dados resultantes por intermédio do cálculo, é possível obter dados matriciais que variam de +1 até -1 em diferentes escalas de cinza para categorizar os níveis da densidade da vegetação presente na área calculada.

Os resultados do NDVI foram projetados em suas convenções cartográficas, para um melhor trabalho e realização de cálculos posteriores, para a projeção UTM WGS 84 zona 24 Sul.

Com as mesmas bandas utilizadas para o cálculo do NDVI, foi gerado o SAVI, o índice de vegetação ajustado para o solo, que pode resultar numa variação de 0 até 1 , utiliza em sua equação uma constante representada por L que é corresponde geralmente a 0,5 , o resultado do SAVI também foi projetado em suas convenções cartográficas, para a projeção UTM WGS 84 Zona 24 sul, usando para conseguir o SAVI foi utilizado a equação:

\section{SAVI $=(\mathbf{I}+\mathbf{L})(\mathbf{I V P}-\mathrm{V}) /(\mathbf{L}+\mathbf{I V P}+\mathrm{V})$}

Ainda com as bandas 5 e 4 do sensor OLI, foi gerado o SR, índice de vegetação por razão simples, que foi o pioneiro em divisão de bandas, seu resultado também foi refeita a projeção em suas convenções cartográficas para UTM WGS 84 Zona 24 sul. Para o SR foi o usado a divisão de bandas como pode ser verificada em:

\section{$S R=I V P / V$}


Utilizando o mesmo método que uniu as duas cenas da SRTM, uniu-se os dois resultados do cálculo do NDVI, SAVI e SR em apenas um mosaico.

Tendo o perímetro da bacia hidrográfica delimitada, pode-se utilizá-lo para então extrair do resultado total do NDVI, SAVI e SR que é toda a cena fotografada pelo Landsat 8, e então só obter a área da bacia hidrográfica que é o alvo do estudo e da caracterização da densidade da vegetação.

\section{RESULTADOS E DISCUSSÃO}

Com a classificação supervisionada para a formulação de um mapeamento da densidade da vegetação na área da bacia hidrográfica do rio Paraíba do Meio, foi possível ver com clareza onde cada densidade de vegetação localiza-se dentro do perímetro da localidade estudada, pode-se notar um alto nível de ausência de vegetação nas áreas próximas a nascente da bacia, o que vai contra as leis do código florestal, quando diz que existe um número correto de $\mathrm{Km}^{2}$ que deve existir nos arredores das nascentes, no caso, 50 metros, fazendo com que as águas das nascentes possam ser contaminadas com uma maior facilidade desde sua fonte, além de eventualmente facilitar e potencializar a erosão da área, fazendo com que o rio diminua sua vazão em todo seu percurso, pelo assoreamento dos córregos próximos à nascente.

Ao longo de seu percurso a maior parte da vegetação no meio da bacia acaba por ser rasteira, salvo apenas por algumas áreas próximas ao seu centro, onde há índices de vegetação de alta densidade.

A vegetação arbustiva ocorre principalmente próxima dos cursos do rio quando este aproxima-se de sua foz, com alguns índices de vegetação de alta densidade, chegando perto do grande lago onde as águas da bacia desembocam pode ser encontrado vegetação de alta densidade.

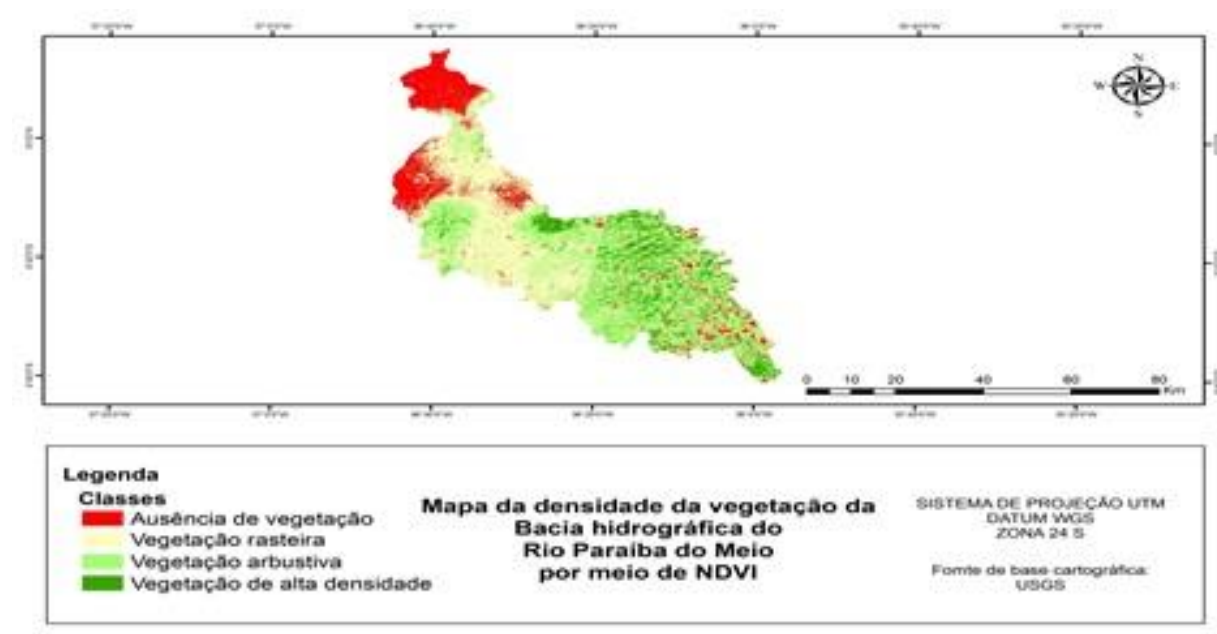

Figura 02: Mapa da densidade da vegetação da bacia hidrográfica do rio Paraíba do Meio por meio de NDVI. Fonte:

Autor Renilson Pinto da Silva Ramos.

Quando feita a comparação entre os índices de vegetação com o propósito de ter uma maior precisão na classificação dos alvos e conseguir garantir resultados ainda melhores, foi possível verificar resultados com algumas divergências, com essa comparação foi possível garantir a veracidade resultados obtidos, nas classes de ausência de vegetação e de vegetação rasteira foi possível ver as menores diferenças entre os três índices, o NDVI e o SAVI apresentaram resultados próximos na classe de vegetação arbustiva, o SR apresentou uma 
discrepância em comparação aos dois outros índices, com uma menor quantia nessa classe, a maior diferença entre os três índices foi encontrado na classe de vegetação de alta densidade, variando entre os três índices em seus resultados, os dados podem ser melhor observados nas tabelas e gráficos.

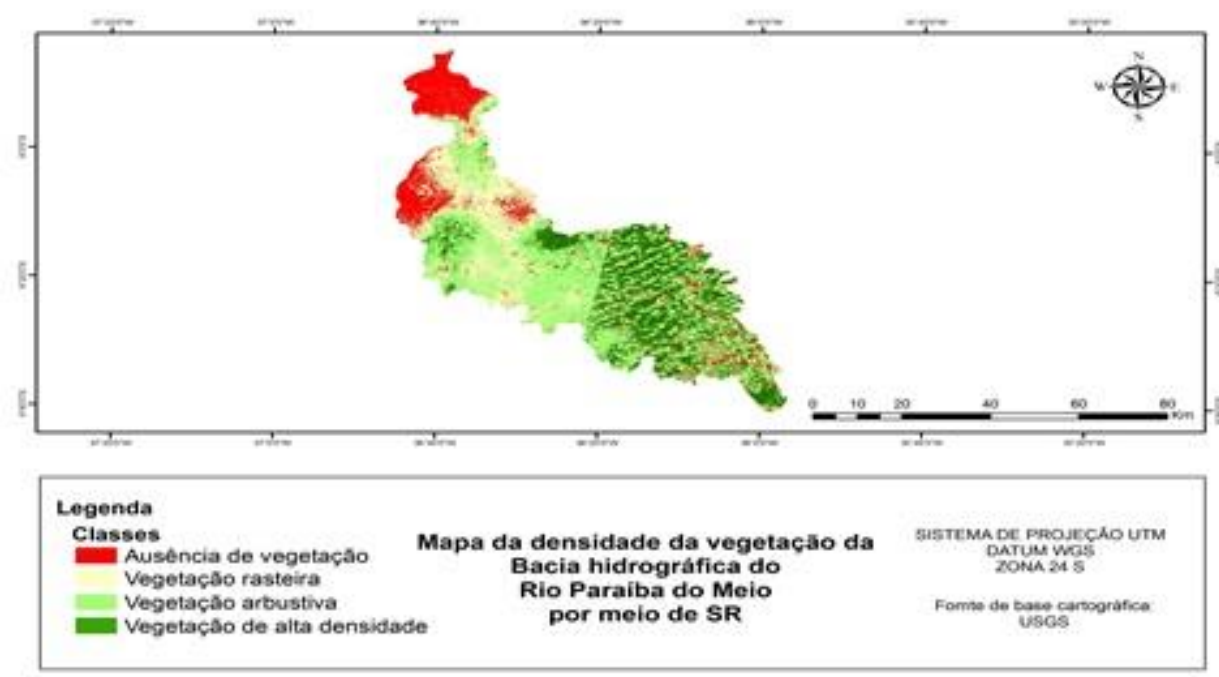

Figura 03: Mapa da densidade da vegetação da bacia hidrográfica do rio Paraíba do Meio por meio de SR. Fonte: Autor Renilson Pinto da Silva Ramos.

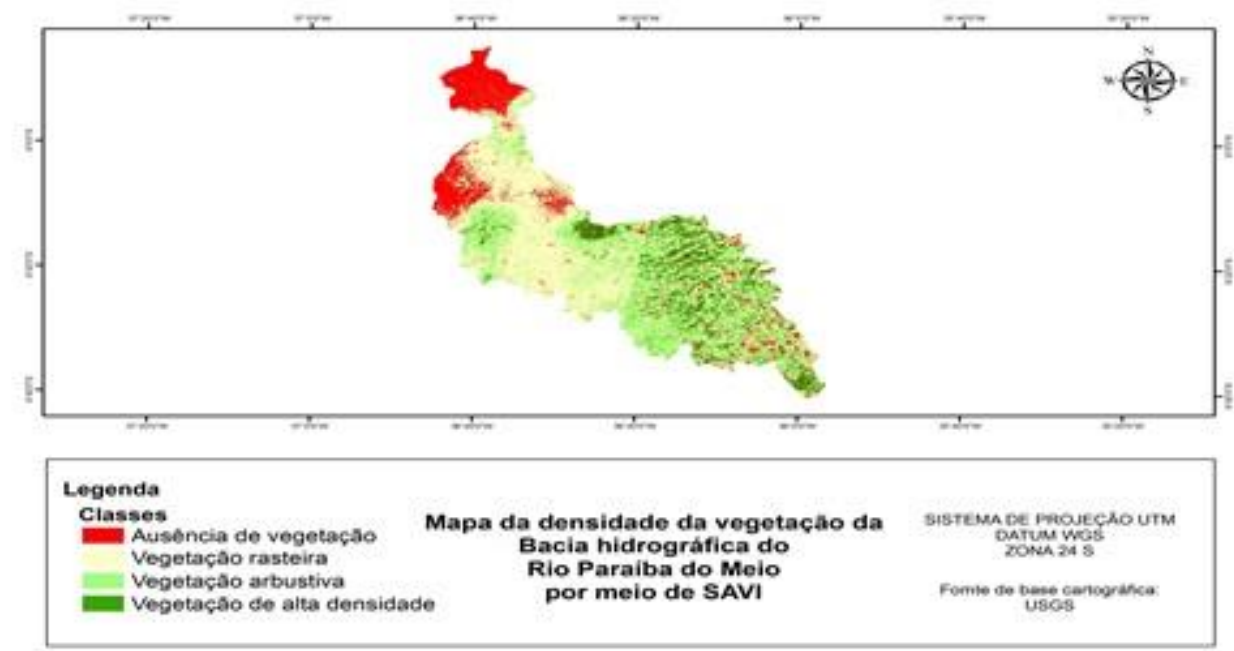

Figura 04: Mapa da densidade da vegetação da bacia hidrográfica do rio Paraíba do Meio por meio de SAVI. Fonte: Autor Renilson Pinto da Silva Ramos.

Tabela 01: Classes da vegetação do NDVI por Km². Fonte: Autor Renilson Pinto da Silva Ramos. 


\begin{tabular}{c|c}
\hline Classes & Área em $\mathrm{Km}^{2}$ \\
\hline Ausência de vegetação & 365,23 \\
\hline Vegetação rasteira & 1137,21 \\
\hline Vegetação arbustiva & 1141,04 \\
\hline Vegetação de alta densidade & 503,32 \\
\hline Total & 3136,8 \\
\hline
\end{tabular}

Tabela 02: Classes da vegetação do NDVI por porcentagem. Fonte: Autor Renilson Pinto da Silva Ramos.

\begin{tabular}{c|c}
\hline Classes & Área em \% \\
\hline Ausência de vegetação & 11,64 \\
\hline Vegetação rasteira & 36,25 \\
\hline Vegetação arbustiva & 36,38 \\
\hline Vegetação de alta densidade & 16,04 \\
\hline Total & $100 \%$ \\
\hline
\end{tabular}

Tabela 03: Classes da vegetação do SAVI por $\mathrm{Km}^{2}$. Fonte: Autor Renilson Pinto da Silva Ramos.

\begin{tabular}{c|c}
\hline Classes & Área em $\mathrm{Km}^{2}$ \\
\hline Ausência de vegetação & 453,81 \\
\hline Vegetação rasteira & 1220,88 \\
\hline Vegetação arbustiva & 1094,36 \\
\hline Vegetação de alta densidade & 367,76 \\
\hline Total & 3136,8 \\
\hline
\end{tabular}

Tabela 04: Classes da vegetação do SAVI por porcentagem. Fonte: Autor Renilson Pinto da Silva Ramos.

\begin{tabular}{c|c}
\hline Classes & Área em \% \\
\hline Ausência de vegetação & 14,57 \\
\hline Vegetação rasteira & 38,92 \\
\hline Vegetação arbustiva & 34,89 \\
\hline Vegetação de alta densidade & 11,72 \\
\hline Total & $100 \%$ \\
\hline
\end{tabular}

Tabela 05: Classes da vegetação do SR por $\mathrm{Km}^{2}$. Fonte: Autor Renilson Pinto da Silva Ramos.

\begin{tabular}{c|c}
\hline Classes & Área em Km² \\
\hline Ausência de vegetação & 470,98 \\
\hline Vegetação rasteira & 1223,09 \\
\hline Vegetação arbustiva & 762,80 \\
\hline Vegetação de alta densidade & 689,96 \\
\hline Total & 3136,8 \\
\hline
\end{tabular}

Tabela 06: Classes da vegetação do SAVI por porcentagem. Fonte: Autor Renilson Pinto da Silva Ramos.

\begin{tabular}{c|c}
\hline Classes & Área em \% \\
\hline Ausência de vegetação & 14,87 \\
\hline Vegetação rasteira & 38,99 \\
\hline Vegetação arbustiva & 24,32 \\
\hline Vegetação de alta densidade & 21,99 \\
\hline Total & $100 \%$
\end{tabular}


A ausência de vegetação caracterizou-se como a classe com a representação de menor área dentro do perímetro da bacia nos três índices, com apenas $365,23 \mathrm{Km}^{2}$, tendo 11,64\% da área da bacia hidrográfica no NDVI, $453,81 \mathrm{Km}^{2}$, que é $14,57 \%$ no SAVI e $470,98 \mathrm{Km}^{2}$ cobrindo $14,87 \%$ da área no SR, entretanto, sua maior parte acaba por ser encontrada bem próxima de sua nascente. A vegetação rasteira que configura-se ao centro da área da bacia hidrográfica, é uma das duas classes mais presentes na bacia, no NDVI se apresenta com 1137, $21 \mathrm{~km}^{2}$, que possui cerca de 36,25\% da área que compreende a bacia hidrográfica, 1220,88 $\mathrm{Km}^{2}$ da área, que corresponde a 38,92\% no SAVI, e no SR apresenta área de 1223,09, com um número de $38,99 \%$. A vegetação arbustiva que encontra-se em sua maior parte quando rio aproxima-se de sua foz, é que é possuidora de uma área, com 1141, $04 \mathrm{Km}^{2}$, a classe que abrange a maior área da bacia, com 36,38\% no NDVI, no SAVI apresenta área de 1094,36 Km², que é 34,89\% da área da bacia, e no SR apresenta 762,80 $\mathrm{Km}^{2}$, cobrindo 24,31\% da área. A vegetação de alta densidade acabou possuindo no NDVI 503, $32 \mathrm{Km}^{2}$ da área da bacia hidrográfica, correspondendo a $16,04 \%$, no SAVI foi encontrada com $367,76 \mathrm{Km}^{2}$, com $11,72 \%$ da área da bacia hidrográfica, no SR foi encontrado cobrindo $689,96 \mathrm{Km}^{2}$ da área da bacia, correspondendo a $21,99 \%$ nesse índice de vegetação, podendo ser encontrada perto da foz da bacia hidrográfica, como em algumas áreas de reserva legal próxima ao seu centro, como pode ser visto nas tabelas, e as comparações entre os níveis dos índices de cada classe e as divergências entre os índices encontrados podem ser melhor visualizados no gráfico.

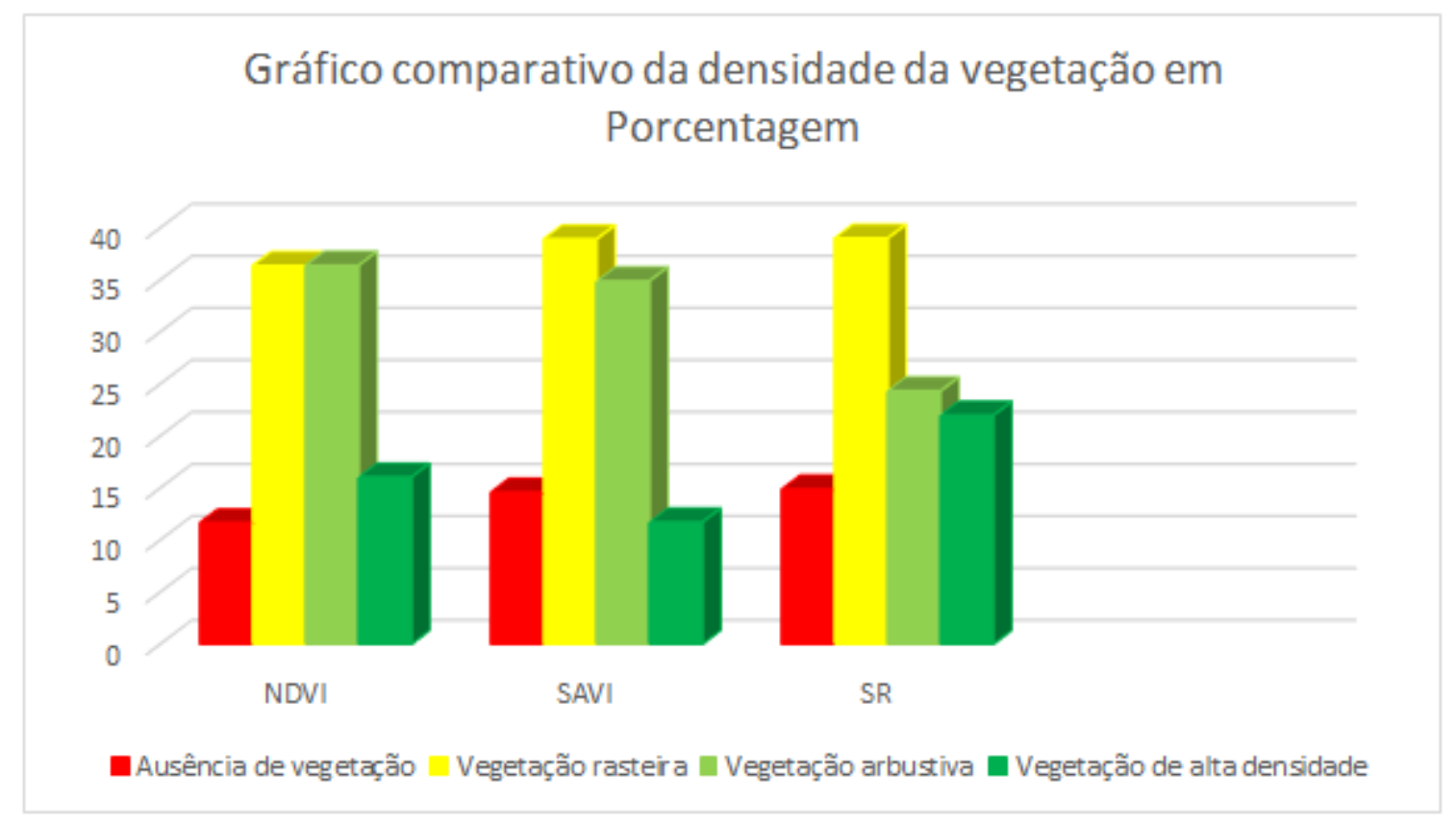

Figura 05: Gráfico comparativo da densidade da vegetação em porcentagem. Fonte: Autor Renilson Pinto da Silva Ramos.

\section{CONSIDERAÇÕES FINAIS}

Foi possível verificar que o NDVI, SAVI e SR que são caracterizados como índices de vegetação eficazes para a medição da densidade da vegetação e como ela aparece por intermédio dos dados auferidos com sensoriamento remoto. 
Com os valores auferidos através das análises da densidade da vegetação, se pode definir a quantidade e os locais da bacia hidrográfica onde determinado tipo de densidade de vegetação aparece, e em que quantidade. A erosão é algo comum dentro de bacia hidrográfica, entretanto, a ausência de vegetação em locais, como na nascente, acabam trazendo problemas para o desenvolvimento do rio, assim causam riscos aos recursos hídricos da bacia.

Tendo em vista a análise da vegetação é uma importante ferramenta para definir diversos fatores que influenciaram na dinâmica da bacia hidrográfica, podendo influenciar índices pluviométricos, ajudar a definir ciclo hidrológico, assim como ajudar na medição de graus de erosão, o conhecimento da densidade de sua vegetação e de onde ela fica, facilita assim, junto com outros trabalhos, a formulação de planejamentos, com a visualização do potencial econômico da área que compreende o perímetro da bacia hidrográfica em questão, fazendo com que assim melhores planos sejam executados e acaba consequentemente haver uma resposta social e econômica da melhor forma possível.

\section{REFERÊNCIAS}

BRASIL, Lei 9. 433 de 8 de Janeiro de 1997. Institui a Política Nacional de Recursos Hídricos, cria o Sistema Nacional de Gerenciamento de Recursos Hídricos, regulamenta o inciso XIX do art. 21 da Constituição Federal, e altera o art. $1^{\circ}$ da Lei ${ }^{\circ}$ 8.001, de 13 de março de 1990, que modificou a Lei $n^{\circ}$ 7.990, de 28 de dezembro de 1989. Diário Oficial da União, Brasília, DF (1997). Disponível em: < http://www.planalto.gov.br/ccivil_03/leis/L9433.htm>. Acesso em: 02/07/2016.

FITZ, P. R. Geoprocessamento sem Complicação. São Paulo, Oficina de Textos, 2008.

LIMA, Carlos Eduardo Santos de. GOMES, Daniel Dantas Moreira. LIMA, Djenane Regina Maia de. DEUS, Rodolfo Alexandre da Silva Gomes de. COSTA, Samuel Othon de Souza. Análise multitemporal da cobertura vegetal do município de Garanhuns - PE, através dos dados de NDVI. Anais XVII Simpósio Brasileiro de Sensoriamento Remoto - SBSR, João Pessoa-PB, Brasil, 25 a 29 de abril de 2015, INPE.

O Novo Código Florestal. Disponível em: <http://abmra.org.br/abmrablog/?p=550>. Acesso em: 02/07/2016.

PONZONI, F.J. SENSORIAMENTO REMOTO NO ESTUDO DA VEGETAÇÃO: DiAgNOSTICANDO A MATA ATLÂNTICA. INSTITUTO NACIONAL DE PESQUISAS ESPACIAIS - INPE. São José dos Campos, 2002.

ROSS, Jurandyr Luciano Sanches. Geomorfologia-Ambiente e planejamento. Editora contexto, 1991.

TRICART, Jean. Ecodinâmica. IBGE, 1977. 


\section{AGRADECIMENTOS}

Os autores agradecem ao Conselho Nacional de Desenvolvimento Científico e Tecnológico (CNPq) pelo financiamento dos recursos do projeto de pesquisa "Diagnóstico geoambiental das bacias hidrográficas do Estado de Pernambuco: geoprocessamento aplicado ao manejo e conservação dos recursos naturais", junto ao Programa Institucional de Bolsas de Iniciação Científica (PIBIC) da Universidade de Pernambuco (UPE), e ao Laboratório de Geoprocessamento e Modelagem Ambiental pela cessão dos dados cartográficos vetorizados e imagens de satélites.

Recebido em: 14/08/2016

Aceito para publicação em: 01/10/2016 